\title{
Development and implementation of a Greater Manchester COVID19 Urgent Eyecare Service
}

\author{
Robert A. Harper ${ }^{1,2} \cdot$ Felipe Dhawahir-Scala ${ }^{1} \cdot$ Helen Wilson $^{1} \cdot$ Patrick J. G. Gunn ${ }^{1,2} \cdot$ Matthew Jinkinson $^{3,4}$. \\ lain A. Pretty ${ }^{5}$. Sara Fletcher ${ }^{6}$ - William D. Newman ${ }^{1}$
}

Received: 5 June 2020 / Revised: 10 June 2020 / Accepted: 11 June 2020 / Published online: 29 June 2020

(c) The Royal College of Ophthalmologists 2020

In response to COVID19, NHS England/Improvement (NHSE/I) set out that alongside routine General Ophthalmic Services (GOS) sight testing ceasing (and acknowledging that the remaining essential GOS is not an urgent or emergency service), urgent eye care would need to be commissioned and delivered through a contract with local commissioners [1].

In April 2020 the Royal College of Ophthalmologists [2] and the College of Optometrists [3] welcomed the COVID19 Urgent Eyecare Service (CUES) specification published by NHSE/I, affording clarity over arrangements enabling patients to access urgent eye care in the community, with only high-risk patients requiring referral to hospital ophthalmic emergency services. This single specification service is intended to be delivered via primary care optometrists acting as urgent eyecare hubs, supported by hospital ophthalmology, and commissioned locally by Clinical Commissioning Groups (CCGs).

Robert A. Harper

robert.harper@mft.nhs.uk

1 Manchester Royal Eye Hospital and Manchester Academic Health Sciences Centre, Manchester University NHS Foundation Trust Manchester, Manchester M13 9WL, UK

2 Division of Pharmacy and Optometry, School of Health Sciences, Faculty of Biology, Medicine and Health, University of Manchester, Manchester M13 9PL, UK

3 Greater Manchester Eye Health Network, Health \& Social Care Partnership, 3 Piccadilly Place, London Road, Manchester M1 3BN, UK

4 Primary Eyecare Service, 2.3 Waulk Mill, 51 Bengal Street, Manchester M4 6LN, UK

5 Division of Dentistry, School of Medical Sciences, University of Manchester, Manchester M13 9PL, UK

6 Manchester Clinical Commissioning Group, 1st Floor, Parkway 1, Parkway Business Centre, Princess Road, Manchester M14 7 LU, UK
In this article, we describe the development of CUES in Manchester and Greater Manchester (GM), noting opportunities afforded with requirement for rapid implementation of a new service, albeit one building on existing collaborations, capitalising on new technology and the emergence of a critical mass of optometrists with Independent Prescribing (IP) accreditation. We emphasise the importance of collaboration, including clinicians in primary and secondary care, commissioners, and technology providers.

Manchester has a longstanding tradition of locally commissioned services, being first to establish a glaucoma referral filtering service [4], implementing a pathway refined over the years alongside changes in national guidance [5-8]. Facilitated by this history of engagement, and indeed prior to COVID19, discussions had been held to establish ways in which primary and secondary care ophthalmic services might be enhanced, recognising capacity limitations within hospital ophthalmology, the evolving scope of practice of optometrists, and recommendations from: Royal College of Ophthalmologists [9]; the Clinical Council for Eye Health Commissioning [10]; NHSE's elective care transformation programme [11]; and the Ophthalmology GIRFT Programme [12]. Local enablers in developing CUES included.

First, the Manchester and GM locality is served by Primary Eyecare Services (PES), an Optometry Federation established by Local Optical Committees in England, and the largest provider of 'extended' PES delivered via a network of optometry practices. PES hold contracts with a number of CCGs to deliver extended PES including glaucoma, cataract and minor eye conditions. PES had a current contractual arrangement with Manchester CCG facilitating their ability to effectively commission CUES through a contract variation.

Second is the availability of the OPERA (OPtometric Electronic Referral and Assessment) platform for managing referrals. The system brings NHS IT infrastructure into primary care optometry, facilitating appropriate role 


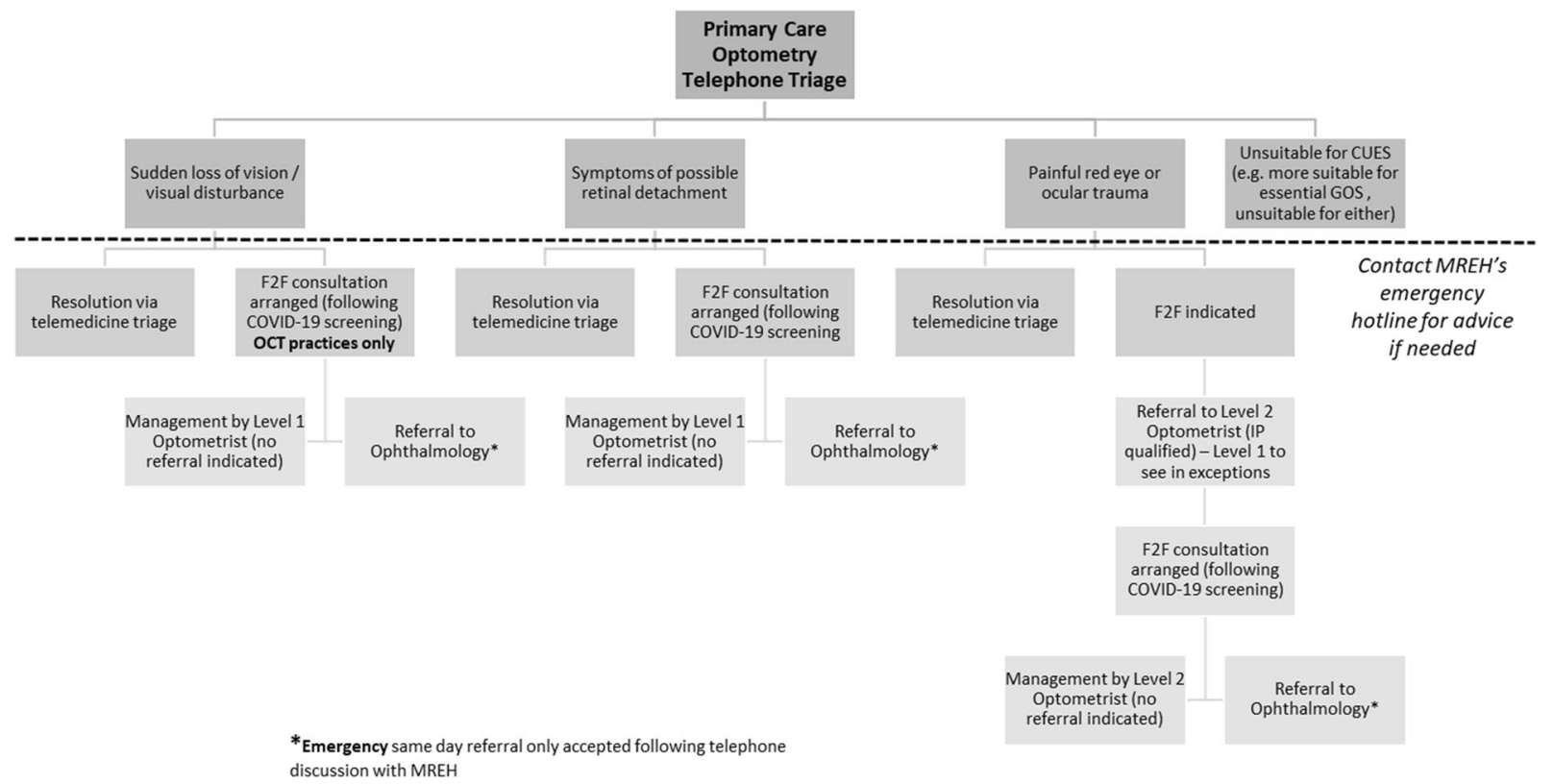

Fig. 1 Summary clinical pathway for the Manchester CUES. Key: Face to face consultation F2F, General Ophthalmic Services GOS, Level 2 optometrist has the Independent Prescribing, IP, qualification.

based access to NHS number lookup and, for urgent care cases, the Summary Care Record (SCR). Once completed primary care assessments can be sent to the NHS e-Referral Service (e-RS). Significantly Opera integrates with hospital Picture Archiving Communication Systems (PACS), Patient Administration Systems and allows notifications of referrals through the system. The former allows optometrists to attach non-degraded images alongside referrals, including volumetric OCT analysis, of particular value to the urgent macula referral arm within CUES. A related practice-based enabler is the growing number of practices with OCT and/or other imaging, which for the first time locally allows for image transfer consistent with NHS Digital's requirements. Images uploaded to OPERA PACS can be viewed in primary and secondary care and sent onwards for integration into other imaging and reporting platforms. The use of triage functions within e-RS enables two-way correspondence between primary and secondary care. While developed in response to urgent care, the system offers opportunities to develop collaborations for future shared care models.

Third is the growing number of optometrists within GM with the IP qualification. These practitioners largely had their courses funded through Health Education England, with clinical placements being within local eye units, notably Manchester Royal Eye Hospital (MREH). This arrangement confers feasibility for using a second level of optometric practitioner for inter-optometric referral of selected cases following initial telephone triage, allowing a more complex patient case mix to be assessed and managed within CUES than would otherwise have been the case.

Finally, there is the local engagement such that in anticipation of the NHSE/I service specification on CUES published in mid-April 2020, a collaboration of GM LEHN, Manchester CCG and MREH worked on plans in March 2020 to develop an urgent eyecare service in supporting immediate and recovery phases of the Coronavirus Pandemic. Setting up CUES required collaboration across the system, with primary and secondary care clinicians working together to develop the pathway (see Fig. 1). The intention is to safely deliver urgent eye care in the community using remote triage and consultations by telemedicine, minimising face-to-face appointments, making use of technology to allow for advice around referrals via e-RS, and reducing burdens on the rest of primary care and within secondary care. While the Manchester CUES was intended to align with the generic NHSE/I specification, it was intended to make use of local opportunities, as outlined above, with clinicians within MREH's acute services developing clinical guideline documentation and a prescribing formulary (Table 1).

The launch event for the service in Manchester and elsewhere also reflected our collaboration, in having optometrists expressing an interest in providing CUES attend a joint MREH and PES webinar via Microsoft Teams, providing explanations of the pathway and clinical scenarios, as well as reviewing administrative and contract related requirements. The service has now been implemented in six 
Table 1 Manchester CUES formulary for optometrists (including those with $\mathrm{IP}^{\mathrm{a}}$ ), summarising the provisional list of pharmacological treatments, and anticipated indications, at the commencement of the service and to be prescribed via FP10s in the community.

\begin{tabular}{|c|c|c|c|c|}
\hline Medication & Form & Strength & Quantity & Indications \\
\hline \multicolumn{5}{|l|}{ Anti-infectives } \\
\hline Chloramphenicol $^{\mathrm{a}}$ & Eye drops & $0.5 \%$ & $10 \mathrm{ml}$ & $\begin{array}{l}\text { Corneal abrasion } \\
\text { Post FB removal }\end{array}$ \\
\hline Chloramphenicol $^{\mathrm{a}}$ & Eye ointment & $1 \%$ & $4 \mathrm{~g}$ & $\begin{array}{l}\text { Corneal abrasion } \\
\text { Hordeolum }\end{array}$ \\
\hline Fusidic acid & Eye drops & $1 \%$ & $5 \mathrm{~g}$ & \\
\hline Ofloxacin $^{\mathrm{a}}$ & Eye drops & $0.3 \%$ & $5 \mathrm{ml}$ & $\begin{array}{l}\text { Abrasion AND contact } \\
\text { lens wearer } \\
\text { CL-related keratitis }\end{array}$ \\
\hline Ganciclovir $^{\mathrm{a}}$ & Eye gel & $0.15 \%$ & $5 \mathrm{~g}$ & Herpes simplex keratitis \\
\hline \multicolumn{5}{|l|}{ Ocular lubricants } \\
\hline Hypromellose & Eye drops & $0.5 \%$ & $10 \mathrm{ml}$ & Symptoms of dry eye \\
\hline Carbomer 980 & Eye gel & $0.2 \%$ & $10 \mathrm{~g}$ & $\begin{array}{l}\text { Symptoms of dry eye } \\
\text { Conjunctivitis } \\
\text { Episcleritis }\end{array}$ \\
\hline $\begin{array}{l}\text { Liquid paraffin and white soft } \\
\text { paraffin }\end{array}$ & Eye ointment & & & $\begin{array}{l}\text { Symptoms of dry eye } \\
\text { Entropion and ectropion }\end{array}$ \\
\hline $\begin{array}{l}\text { Sodium hyaluronate } \\
\text { preservative free }\end{array}$ & Eye drops & $0.15 \%$ & $10 \mathrm{ml}$ & $\begin{array}{l}\text { If sensitive to preservatives or } \\
\text { frequent use }\end{array}$ \\
\hline \multicolumn{5}{|c|}{ Antihistamines and mast cell stabilisers } \\
\hline $\begin{array}{l}\text { Antazoline and xylometazoline } \\
\text { (Otrivine-Antistin) }\end{array}$ & Eye drops & $0.5 \% / 0.05 \%$ & $10 \mathrm{ml}$ & Allergic conjunctivitis \\
\hline Sodium cromogylcate & Eye drops & $2 \%$ & $10 \mathrm{ml}$ & Allergic conjunctivitis \\
\hline \multicolumn{5}{|l|}{ Corticosteroids } \\
\hline Prednisolone acetate $^{\mathrm{a}}$ & Eye drops & $1 \%$ & $5 \mathrm{ml}$ & Recurrent anterior uveitis \\
\hline \multicolumn{5}{|l|}{ Antimuscarinics } \\
\hline Cyclopentolate hydrochloride ${ }^{\mathrm{a}}$ & Eye drops & $1 \%$ & $5 \mathrm{ml}$ & Recurrent anterior uveitis \\
\hline
\end{tabular}

${ }^{a}$ Therapeutics available to IP optometrists within CUES.
CCGs (as of 1st June 2020) within the GM conurbation, with referrals including images and SCR through e-RS and NHSmail.

CUES is commissioned in Manchester for 6 months but is expected to have relevance thereafter, being flexible enough to accommodate changes or additional arrangements around referral, whether urgent, as is the case here, or routine, capitalising on the collaboration and IT capabilities beyond CUES. We believe that a key strength of the development and implementation described herein is stakeholder engagement in an increasingly complex NHS commissioning landscape. NHSE/I have proposed a number of expected benefits of CUES, not least safe and effective reduction in ophthalmology attendances. An evaluation across primary and secondary care is planned to address the all-important question of whether CUES will reduce the queues.

Acknowledgements The authors wish to acknowledge the support of the following in developing and implementing this service: Sajjad Mahmood, Yvonne D'Souza and Reshma Thampy (consultant ophthalmologists, MREH); Wendy Craven (Clinical Governance and Performance Lead for PES); Rebecca Rietdyke (Chair of Manchester LOC); Dawn Barnes, Prajakta Gaikwad and Jonathan Trzos (Nurse Practitioner team,
Emergency Eye Department, MREH); and Dean Bryan, Annie Nicholas and Katie James (MREH eRS, administration and communications).

\section{Compliance with ethical standards}

Conflict of interest IAP is the clinical lead at FDS Consultants, responsible for the OPERA system. MJ is Clinical Director at Primary Eyecare Services, holder of the contract with Manchester CCG in relation to CUES and other primary care optometry delivered services.

Publisher's note Springer Nature remains neutral with regard to jurisdictional claims in published maps and institutional affiliations.

\section{References}

1. COVID-19 Urgent Eyecare Service - CUES. (NHS England Publication approval reference: 001559) 2020.

2. https://www.rcophth.ac.uk/2020/04/nhse-i-commission-urgent-eyeca re-service-in-response-to-covid-19-supporting-management-of-a ppropriate-referrals-from-eye-care-hubs-to-ophthalmology-eye-units/. Accessed 3 June 2020.

3. https://www.college-optometrists.org/the-college/media-hub/new s-listing/nhs-england-covid-19-urgent-eyecare-service-cues.html. Accessed 3 June 2020.

4. Henson DB, Spencer AF, Harper R, Cadman EJ. Community refinement of glaucoma referrals. Eye. 2003;17:21-6. 
5. Konstantakopoulou E, Harper RA, Edgar DF, Lawrenson JG. A qualitative study of stakeholder views regarding participation in locally commissioned enhanced optometric services. BMJ Open. 2014;4:e04781.

6. Baker H, Harper RA, Edgar DF, Lawrenson JG. Multi-stakeholder perspectives of locally commissioned enhanced optometric services. BMJ Open. 2016;6:e11934 https://doi.org/10.1136/bmjopen-2016011934

7. Gunn PG, Marks JR, Konstantakopoulou E, Edgar DF, Lawrenson JG, Roberts S, et al. Clinical effectiveness of the Manchester Glaucoma Enhanced Referral Scheme. Br J Ophthalmol. 2019;103: 1066-71.

8. Forbes H, Sutton M, Edgar D, Lawrenson JG, Spencer AF, Fenerty $\mathrm{C}$, et al. The impact of the Manchester Glaucoma Enhanced Referral scheme on NHS costs. BMJ Open Ophthalmol. 2019;4:e00278 https://doi.org/10.1136/bmjophth-2019-000278
9. Royal College of Ophthalmologists, The Way Forward-Emergency Eye Care 2017. https://www.rcophth.ac.uk/wp-content/uploads/2015/ 10/RCOphth-The-Way-Forward-Emergency-Eye-Care-Summary300117.pdf

10. Clinical Council for Eye Health Commissioning (CCEHC) System and Assurance Framework for Eye-health (SAFE) -Emergency and Urgent Care. 2018. https://www.college-optometrists.org/uploads/a ssets/e827d379-9165-4656-9458c83b0e33da79/SAFE-Emergency-a nd-Urgent-Care.pdf

11. Transforming elective care services ophthalmology. https://www. england.nhs.uk/wp-content/uploads/2019/01/ophthalmologyelective-care-handbook-v1.1.pdf. Accessed 3 Jun 2020.

12. MacEwen C, Davi A, Chang L. Ophthalmology GIRFT Programme National Specialty Report, 2019. https://gettingitrightfirsttime.co. uk/wp-content/uploads/2019/12/OphthalmologyReportGIRFT19PFINAL.pdf. Accessed 3 Jun 2020. 